\title{
Errafum
}

\section{Erratum to: A Study of Reproducibility of a Full-Scale Multi-Room Compartment Fire Experiment}

Nils Johansson*, Stefan Svensson and Patrick van Hees, Department of Fire Safety Engineering, Lund University, Lund, Sweden

\section{Erratum to: Fire Technology DOl: $10.1007 / \mathrm{s} 10694-014-0408-3$}

The dimensions given in Figures 1 and 2 in the original publication contain errors. These errors are corrected in this erratum.

The tests were performed in an apartment on the first floor located $3 \mathrm{~m}$ above ground level. The walls in the experimental setup were made of lightweight concrete (blocks) with a cement-based coating and with a total thickness of approximately $300 \mathrm{~mm}$. The dimensions in Figures 1 and 2 in this erratum are given from enclosure surface to enclosure surface (i.e. the thickness of walls are not included).

* Correspondence should be addressed to: Nils Johansson, E-mail: nils.johansson@brand.lth.se The online version of the original article can be found under doi:10.1007/s10694-014-0408-3. 


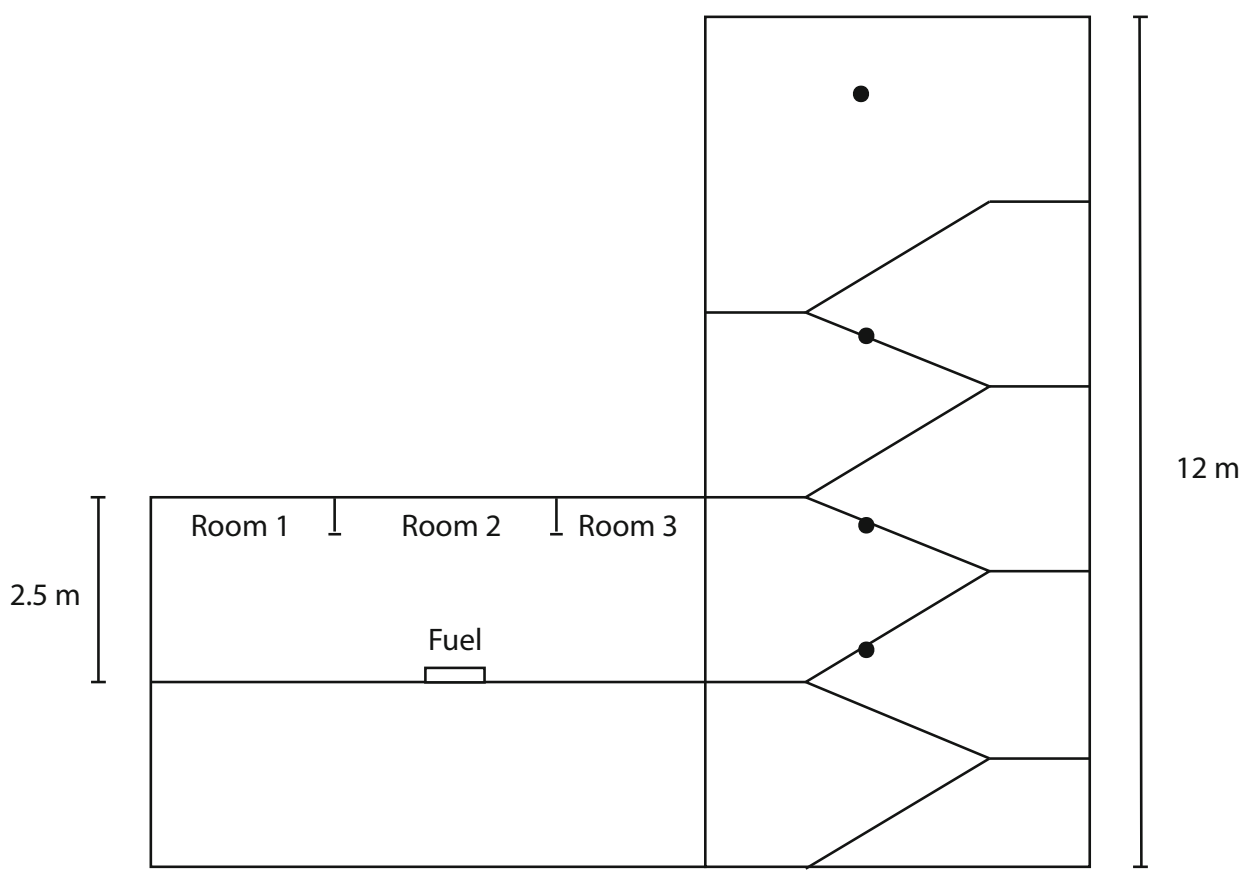

Figure 1. Section drawing of the building.

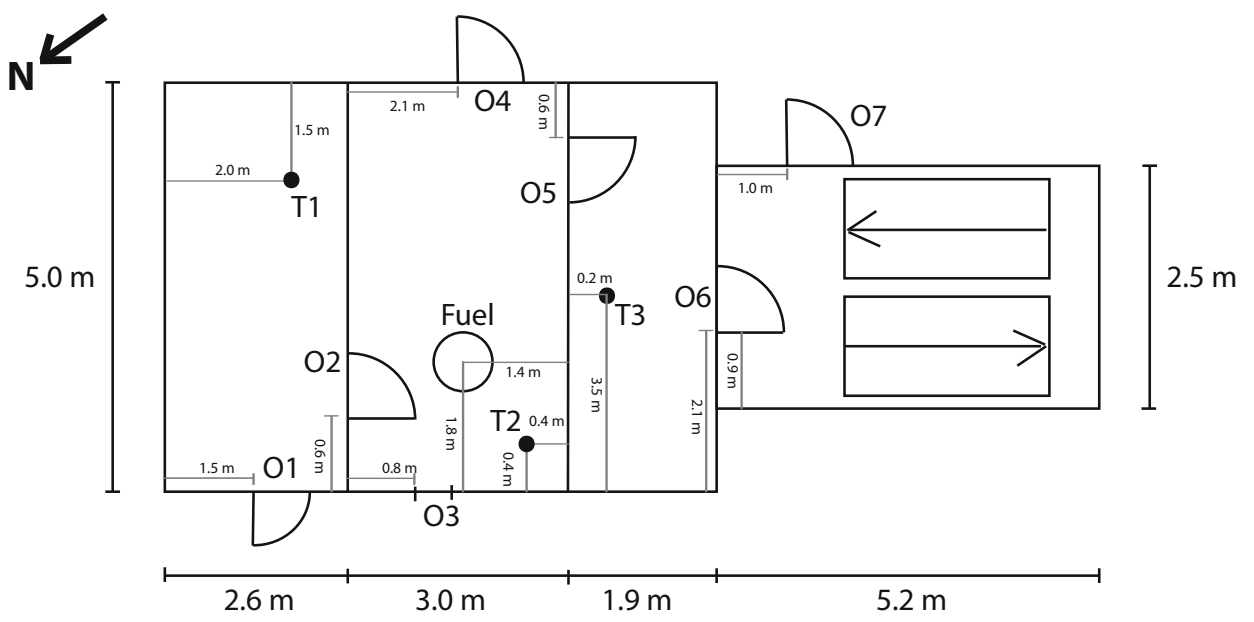

Figure 2. Floor plan with location of openings and equipment. 